\title{
Uma Proposta para o Ensino de Engenharia de Softwa- re a partir da Resolução de Problemas
}

\section{A Proposal to Teach Software Engineering based on Problem Solving}

\author{
Márcia Cristina Cera \\ Universidade Federal do Pampa - \\ UNIPAMPA \\ Campus Alegrete \\ Av Tiarajú, 810, Alegrete, RS \\ marciacera@unipampa.edu.br
}

\author{
Mateus H. Dal Forno \\ Universidade Federal do Pampa - \\ UNIPAMPA \\ Campus Alegrete \\ Av Tiarajú, 810, Alegrete, RS \\ mateush.dalforno@gmail.com
}

\author{
Vanessa Gindri Vieira \\ Universidade Federal de Santa Maria - \\ UFSM \\ Colégio Politécnico \\ Av Roraima, 1000, Santa Maria, RS \\ vanessavieira@politecnico.ufsm.br
}

Resumo Os constantes avanços tecnológicos requerem que os profissionais possuam, além de conhecimento específico, habilidades tais como proatividade, iniciativa, capacidade de autoaprendizagem, de comunicação e de trabalho em equipe. Entretanto, no ensino superior tradicional, geralmente, o foco principal volta-se a aquisição de conhecimento, figurando como um complemento opcional as atividades que estimulam tais habilidades. Buscando estreitar a distância entre o ambiente acadêmico e o cotidiano profissional da área de engenharia de software, idealizou-se o curso de Engenharia de Software (ES) da UNIPAMPA. O método escolhido para apoiar a aproximação entre teoria e prática foi a ABP (Aprendizagem Baseada em Problemas). Além do ensino dos conceitos embasadores, o curso reserva parte de seu período letivo para praticá-los através de disciplinas chamadas de Resolução de Problemas. Nelas, os alunos são estimulados a solucionar um problema real através do desenvolvimento de um sistema computacional. Divididos em equipes, eles aplicam conceitos e práticas da engenharia de software e exercitam a coordenação e o desenvolvimento do projeto de sua equipe, simulando o ambiente de uma empresa de desenvolvimento de software. O objetivo deste artigo é mostrar como o emprego da ABP pode contribuir tanto para a aprendizagem da engenharia de software, quanto para estimular as referidas habilidades profissionais. Como estudo de caso, este artigo apresenta o planejamento e a operacionalização da disciplina de Resolução de Problemas I, que é ofertada aos alunos ingressantes na ES. Através dos retornos obtidos da turma de 2011, percebeu-se que, mesmo com uma visão preliminar do curso, os alunos perceberam a importância do emprego da ABP como meio para estreitar a distância entre a teoria e as práticas profissionais da área de engenharia de software.

Palavras-Chave: Resolução de Problemas, Engenharia de Software, ABP

\begin{abstract}
The constant technological advances require that professionals have, in addition to specific knowledge, skills such as proactivity, initiative, self-learning ability, communication and teamwork. However, in traditional higher education, generally, the focus turns to knowledge acquisition, appearing as an optional activities that encourage such skills. Seeking to narrow the gap between the academic and the job market, is envisioned the Software Engineering (ES) course at UNIPAMPA. The method chosen to support the approximation between theory and practice was the PBL (Problem Based Learning). Besides teaching the basic concepts, the course reserve part of their semester to practice them across disciplines called Problem Solving. In them, students are encouraged to solve a real problem by developing a computer system. Divided into teams, they apply concepts and practices of software engineering and exercise coordination and project development of your team, simulating the environment of a software development company. The aim of this paper is to show how the use of PBL may contribute to both the learning of software engineering, and to encourage professional aimed skills. As a case study, this paper presents the design and operationalization of Problem Solving I, which is offered to freshman students in the ES. Through the returns from the class of 2011, it was realized that even with a preliminary overview of the course, students realized the importance of the use of PBL as a means to bridge the gap between theory and professional practices of software engineering.
\end{abstract}

Keywords: Problem Solving, Software Engineering, PBL 


\section{Introdução}

O mercado de trabalho demanda profissionais capazes de adaptar-se rapidamente às novas tecnologias, e a potencializar suas atividades fazendo uso das mesmas. Neste sentido, é imprescindível ter iniciativa e proatividade para buscar novos conhecimentos, à medida que surgem as demandas. Adicionalmente, espera-se que os profissionais sejam também capazes de estabelecer relações interdisciplinares para propor soluções mais eficazes e coerentes com a realidade atual. Outro fator importante é a capacidade de desenvolver um trabalho em equipe, onde, além de conhecimento, é necessário responsabilidade, comprometimento, divisão de tarefas e coordenação.

O ensino superior também sofre os efeitos dos avanços tecnológicos. Por um lado, espera-se que os meios acadêmicos incorporem as Tecnologias de Informação e Comunicação (TIC), tanto no uso destas para facilitar o aprendizado, quanto para preparar os egressos para as demandas do mercado. Adicionalmente, além da adaptação e incorporação de TIC, também é preciso refletir sobre as metodologias de ensino-aprendizagem utilizadas. O objetivo desta reflexão é encontrar meios de estimular um aprendizado significativo, o qual esteja de acordo com o que o mercado de trabalho demanda.

As metodologias de ensino-aprendizagem tradicionalmente empregadas no ensino superior, em sua grande maioria, estão centradas no ensino. Nestes casos, o estímulo a habilidades ligadas ao trabalho em equipe, proatividade e interdisciplinariedade, figuram como um complemento a formação do perfil do egresso. Entretanto, há uma crescente preocupação em estruturar o processo de ensino-aprendizagem de maneira em que seja possível tornar o ambiente acadêmico mais próximo das situações e dificuldades da realidade do mercado de trabalho [18].

Buscando dar um primeiro passo para aproximar o ambiente acadêmico do mercado profissional, os professores da área de computação da UNIPAMPA, idealizaram o curso de Engenharia de Software (ES). Nele, buscou-se estimular a realização de práticas coletivas em conjunto com o ensino dos conceitos, métodos e tecnologias da área [2, 3, 8]. Com isto, espera-se proporcionar meios que estimulem um aprendizado com forte embasamento teórico-prático, pautado na autoaprendizagem e na aproximação com as práticas profissionais.

Os cursos de Engenharia de Software são recentes no Brasil, embora sejam comuns no exterior, com currículos definidos pela IEEE Computer Society e Association for Computing Machinery (ACM) [10, 24]. No entanto, a demanda para a formação de engenheiros de software é crescente no mercado de tecnologia atual [4]. Como o foco das atividades deste profissional estão voltados ao projeto, desenvolvimento e avaliação de sistemas computacionais, é necessário estimular os acadêmicos a vivenciar este tipo de prática, onde a teoria seja aplicada. A alternativa encontrada para tentar aproximar a teoria e a prática na ES da UNIPAMPA foi através do uso de uma estratégia pedagógico/didática centrada no aluno, denominada Aprendizagem Baseada em Problemas - ABP (Problem Based Learning - PBL) [1,6].

A ABP estimula a discussão entre pequenos grupos de alunos acerca de um problema real, visando encontrar uma maneira de solucioná-lo. Logo, o conhecimento é construído através das iterações entre os alunos, tendo em vista as dificuldades a serem superadas e o ambiente de trabalho em que estão inseridos. Assim, o estudante torna-se responsável pela sua própria aprendizagem [17]. Segundo Souza et al. [23], a ABP visa a construção integrada de conhecimento de forma estruturada ao redor de problemas, no contexto do domínio alvo, com a integração entre os conhecimentos construídos e as condutas para solução desses problemas. Como consequência, têmse o desenvolvimento de habilidades para a aprendizagem autônoma e para o trabalho em equipe. Neste sentido, a ABP foi implementada na ES da UNIPAMPA como meio para estimular a autoaprendizagem, proatividade, iniciativa, coordenação e responsabilidade. Este estímulo se dá como parte do desenvolvimento do trabalho em equipe na busca por soluções a problemas reais.

O curso de ES da UNIPAMPA foi estruturado considerando aspectos ligados a ABP, onde faz parte da formação a aproximação entre teoria e prática formalizada em componentes curriculares chamados Resolução de Problemas. Do primeiro ao sexto semestre do curso, os alunos são estimulados a desenvolverem um sistema computacional que solucione um desafio. Para a confecção da solução, os alunos são divididos em equipes de trabalho simulando um ambiente profissional. Para chegar a uma solução, os alunos precisam aplicar os conceitos de engenharia de software vistos até aquele ponto do curso. Cada equipe de trabalho tem um professor tutor que acompanha suas atividades figurando como um mediador, entretanto, são os próprios estudantes que tomam as decisões durante o desenvolvimento da solução.

O objetivo deste artigo é mostrar que o emprego da metodologia de ensino-aprendizagem ABP, pode contribuir tanto para a aprendizagem da engenharia de software, quanto para estimular habilidades ligadas ao cotidiano profissional. O foco do nosso estudo dirigido é a disciplina de Resolução de Problemas I (RP-I), a qual é ofertada aos alunos ingressantes na ES. Como os acadêmicos ainda estão se familiarizando, tanto com os conceitos e 
práticas de engenharia de software, quanto com o trabalho em equipe, esta disciplina precisa ser apoiada por artefatos apropriados para a criação do hábito da organização e direcionamento das atividades das equipes. Neste artigo, analisaremos a percepção de nossos alunos com base nos retornos obtidos pela turma que cursou RP-I no primeiro semestre de 2011. Buscaremos identificar as reações dos alunos com relação a proposta de construção coletiva do conhecimento através do emprego da ABP na resolução de problemas.

O restante deste artigo está organizado da seguinte forma. A Seção 2 apresenta um apanhado geral sobre a $\mathrm{ABP}$ e o seu emprego em diferentes contextos. A seguir, a Seção 3 discute o emprego da $\mathrm{ABP}$ ligado a área de Engenharia de Software e apresenta a organização curricular da ES da UNIPAMPA. A Seção 4 apresenta detalhes da disciplina de Resolução de Problemas I, a qual é o foco das atividades descritas neste artigo. Detalhes e considerações sobre os artefatos utilizados em RP-I estão descritos na Seção 5. A Seção 6 apresenta a característica da turma de 2011, sua divisão em grupos, os problemas reais que foram alvo das atividades e a atuação dos tutores frente os grupos. Os retornos (feedbacks) da turma de 2011 são apresentados na Seção 7, acompanhados de uma análise sobre as respostas dos acadêmicos. Por fim, há a conclusão deste artigo na Seção 8 acompanhada das referências utilizadas.

\section{ABP em Cursos Superiores}

A Aprendizagem Baseada em Problemas (ABP) surgiu na década de 50 na escola de medicina da Universidade McMaster [21]. Uma de suas principais características é que seu foco é centrado no aluno, e não no ensino [1]. Nela o aprendizado é construído coletivamente através do conhecimento adquirido durante a resolução de desafios [16]. Além de estimular a autoaprendizagem, esta abordagem também proporciona uma prática relacionada ao trabalho em equipe fomentando a responsabilidade, o comprometimento e a coordenação. Assim, a adoção desta abordagem em cursos superiores tem sido considerada uma alternativa eficaz para reduzir a distância entre a teoria, vista no ambiente acadêmico, e as práticas requeridas pelo ambiente profissional $[9,20,23]$.

A ABP é um método de ensino-aprendizagem que pode ser compreendido e implementado de diferentes formas $[1,22]$. Isto permite que a abordagem seja adequada a diferentes áreas de conhecimento e de acordo com as metas almejadas. Esta flexibilidade na adaptação da $\mathrm{ABP}$ tem levado a sua crescente adoção em várias áreas $[1,6,8,13]$. Adicionalmente, a ABP pode ser empregada para estimular um pensamento interdisciplinar incluindo a construção de valores éticos e de cidadania [1]. Um exemplo deste enfoque pode ser visto no projeto acadêmico da USP Leste, que engloba atividades de resolução de problemas desempenhadas por equipes com acadêmicos de diferentes cursos. Cada equipe identifica um problema dentro de sua própria realidade científica cotidiana, discute meios de solucioná-lo, levanta e investiga hipóteses, e, ao final, organiza um relatório acadêmico a partir de suas reflexões [1]. Assim, pontos de vista de áreas distintas são confrontados, alimentando as reflexões em torno da resolução do problema.

O emprego da $\mathrm{ABP}$ na área de Computação é crescente $[9,11,12,14,20,23]$. Esta área possui conceitos que demandam um certo grau de abstração para que possam ser compreendidos. Isto faz com que alguns alunos tenham dificuldades em compreender alguns aspectos ligados a programação e ao funcionamento do computador $[9,12]$. O estimulo a interação entre os acadêmicos gerada pelo emprego da ABP favorece o aprendizado de todos, dando oportunidade aos que possuem dificuldades, de aprender com seus colegas [12].

Adicionalmente, ao aprender pensando na solução de um problema real, os acadêmicos tem uma maior liberdade, podendo experimentar diferentes caminhos para solucionar um problema. Isto evita a pura e simples reprodução do raciocínio de um especialista, estimulando os acadêmicos a chegarem a suas próprias conclusões [23]. O processo de concepção da solução inclui a análise das alternativas, levando ao desenvolvimento do pensamento crítico, da argumentação e julgamentos, além da estruturação do trabalho em equipe nestas condições $[14,20]$. Desta forma, eles tornam-se responsáveis pelas suas escolhas e, consequentemente, capazes de defendê-las, o que poderá ser um diferencial em seus futuros profissionais $[9,14]$.

Para que um profissional da área de computação possa se manter no mercado de trabalho, ele precisa manterse atualizado. $\mathrm{O}$ contato com a ABP durante o aprendizado dos conteúdos básicos, associado a aplicação destes na solução de problemas reais, faz com que os acadêmicos desenvolvam habilidades tais como a autoaprendizagem, proatividade e iniciativa $[9,23]$. Assim, a busca por atualização e aperfeiçoamento será um processo natural frente aos desafios enfrentados na vida profissional, já que seu aprendizado deu-se nestes moldes.

Estas características inerentes do emprego da ABP vem ao encontro dos objetivos do curso de ES da UNIPAMPA, que visa ensinar a engenharia de software preparando os acadêmicos para situações que farão parte de seus cotidianos profissionais. Assim, optou-se pelo emprego da ABP para: fomentar a autoaprendizagem, a proatividade e iniciativa; estimular a construção do conhecimento coletivamente; incentivar a organização do trabalho em equipe e diminuir a distância entre teoria e prática. 
A seguir, será discutida a utilização da $\mathrm{ABP}$ no contexto da Engenharia de Software.

\section{A ABP na Engenharia de Software}

O emprego da ABP na Engenharia de Software tem sido alvo de uma série de estudos, conforme apresentaremos a seguir. Na Seção 3.1 mostraremos os benefícios trazidos pela adoção da abordagem no ensino de engenharia de software. Na Seção 3.2 explicaremos como o curso da UNIPAMPA foi organizado para utilizar a ABP.

\subsection{Adoção da ABP no Ensino da Engenharia de Software}

Quando nos referimos ao ensino da engenharia de software, além de discutir quais tópicos devem ser ensinados, deve-se discutir também como eles serão ensinados [24]. Segundo Schots et al. [18], é importante discutir estratégias para minimizar as dificuldades de ensinoaprendizagem e adaptar o ensino para atender as demandas da indústria de software.

Uma das estratégias que tem sido empregadas na área de engenharia de software é a associação da ABP em projetos $[12,7,15,16]$. Assim, além de estimular o desenvolvimento do raciocínio lógico, da criatividade e mantendo os acadêmicos motivados, é possível aproximar o ensino da engenharia de software às situações vivenciadas no mercado de trabalho.

O desenvolvimento de sistemas de informação reais é uma tarefa complexa, na qual as atividades de construção de software e levantamento de requisitos estão entremeadas: como os requisitos mudam ao longo do ciclo de desenvolvimento, não existe uma divisão clara entre as atividades de construção e levantamento de requisitos. Assim, muitas vezes, a concepção destes sistemas passa pela tomada de decisões com informações incompletas, o que requer uma cuidadosa avaliação para garantir as premissas a partir das quais o desenvolvimento será conduzido. Realizar este processo numa equipe faz com que as vivências de cada um possam servir como um complemento para a elaboração de uma solução eficaz [7, 12]. $O$ trabalho em equipe permite aprimorar a efetividade do aprendizado, preparando os acadêmicos para resolver problemas reais [15].

Outro fator importante vinculado ao uso da ABP na engenharia de software é que a solução acaba tomando um contexto interdisciplinar [5, 7]. Isto porque, para solucionar os problemas, é preciso aplicar vários conceitos, sem a tradicional divisão acadêmica em disciplinas [1].

\subsection{Estrutura do Curso}

Para elaborar a proposta do curso de Engenharia de Software da UNIPAMPA, foram consultados os currículos de referência da IEEE e ACM $[10,24]$. Durante a fase de planejamento do curso, percebeu-se que era importante encontrar meios para aproximar as vivências acadêmicas do cotidiano dos estudantes, com o ambiente de trabalho que eles encontrarão na vida profissional. Para que fosse possível atingir tal objetivo, foram buscadas metodologias alternativas de ensino-aprendizagem, chegandose a $A B P$.

O curso de ES da UNIPAMPA tem duração de quatro anos, organizados em oito semestres, sendo que os dois últimos envolvem atividades vinculadas ao estágio obrigatório e ao Trabalho de Conclusão de Curso. Do primeiro ao sexto semestres, os acadêmicos vivenciam duas fases a cada semestre. Na primeira delas os estudantes recebem os conceitos básicos em componentes curriculares, aos moldes do ensino tradicional. Entretanto, uma boa parcela destes componentes curriculares apresentam os referenciais teóricos de forma concentrada e aplicada. Consequentemente, eles possuem carga horária reduzida e encerram-se no meio do semestre.

Por exemplo, tem-se abaixo os componentes curriculares do primeiro semestre da ES da UNIPAMPA:

- Disciplinas que estendem-se pelas duas fases do semestre:

- Algoritmos e Programação;

- Práticas em Ambientes Computacionais;

- Introdução a Ciência e Tecnologia;

- Disciplinas que encerram-se na primeira fase do semestre:

- Fundamentos de Matemática Discreta;

- Lógica Proposicional;

- Introdução a Engenharia de Software;

- Disciplina exclusiva da segunda fase do semestre que ocupa o espaço das que já se encerraram:

- Resolução de Problemas I.

A partir da metade do semestre inicia-se a segunda fase, onde as disciplinas que já se encerraram cedem espaço para que o trabalho em equipe seja exercitado. Este espaço é formalizado como um componente curricular chamado de Resolução de Problemas (RP) e é onde a ABP é empregada. 
As atividades de RP iniciam-se com a divisão da turma em grupos, os quais organizam-se como se fossem equipes de empresas de projeto e desenvolvimento de software. Em alguns semestres, os acadêmicos escolhem seus parceiros de trabalho, noutros a escolha acontece pelos tutores. Assim, eles passam pela experiência de trabalhar com equipes de perfis diferenciados, exercitando situações que poderão ser frequentes no cotidiano profissional. Os grupos passam a trabalhar na resolução de problemas, onde eles precisam projetar e desenvolver um sistema computacional. Este sistema deve incluir a aplicação prática dos conteúdos vistos até aquele ponto do curso. Consequentemente, ele possui um grau de complexidade compatível com os componentes curriculares trabalhados até o dado semestre.

Santos e Angelo [14] ressaltam a importância da escolha apropriada dos problemas a serem propostos aos acadêmicos para que seja possível atingir as metas previstas com a utilização da ABP. Os problemas precisam ser motivadores e desafiantes para que os acadêmicos questionem-se e sintam-se estimulados a propor uma solução. Assim será possível incentivar a tomada de decisões e a realização de julgamentos, incentivando a autonomia dos grupos. Adicionalmente, os problemas precisam ser complexos o suficiente para que necessitem do trabalho em equipe para que possam ser solucionados [14].

Para estimular e acompanhar a aplicação dos conceitos embasadores, os grupos recebem orientações dos professores que ministraram disciplinas na primeira fase. Cada grupo também conta com um professor tutor que aponta caminhos para a organização do trabalho como uma equipe. $\mathrm{O}$ acompanhamento feito pelo tutor, tanto acontece na sala de aula com a presença de todos os grupos, quanto em atendimento especializado a cada grupo em específico.

A seguir será apresentado o planejamento e acompanhamento da disciplina de Resolução de Problemas I a fim de clarificar as atividades envolvidas e a organização necessária para o bom andamento das atividades.

\section{Estudo Dirigido: Resolução de Pro- blemas}

Este artigo concentra-se na operacionalização da disciplina de Resolução de Problemas I (RP-I), ofertada ao primeiro semestre da ES. Ela possui um desafio extra, pois representa o primeiro contato dos acadêmicos tanto com as práticas da área de engenharia de software, quanto com uma abordagem diferenciada de ensinoaprendizagem como a ABP. Logo, RP-I precisa cativar os alunos ingressantes tanto para as questões de uma área do conhecimento contemporânea e desafiadora como a engenharia de software, quanto para uma forma de aprendi- zagem não convencional e inovadora. Ademais, esta abordagem acompanhará os acadêmicos pelos seus próximos semestres no curso e é importante motivá-los a trabalhar em equipe.

As disciplinas de Resolução de Problemas possuem naturalmente um caráter interdisciplinar, pois unem os conhecimentos trabalhados de forma segmentada nos demais componentes curriculares. No caso específico de RP-I, é esperado que a resolução dos problemas propostos envolva os conhecimentos adquiridos ao longo da primeira fase do semestre (ver exemplo na Seção 3): princípios de lógica e programação; conceitos básicos de projeto de sistemas (levantamento de requisitos, estudos de caso, etc.) e o uso de ambientes computacionais. Durante o planejamento e execução da solução, os acadêmicos também irão aprimorar suas habilidades e conhecimentos através do autoestudo e pela troca de experiências entre colegas. Este último é estimulado pelo emprego da ABP e tem um papel importante, pois permite aos acadêmicos com dificuldades de aprendizado, uma oportunidade de supri-las através da interação com seus colegas.

Para dar suporte a operacionalização de RP-I, foi criado um projeto de ensino. Além de contar com professores da disciplina, o projeto também contou com alunos veteranos, bolsistas do projeto, que já haviam cursado a disciplina. Eles trabalharam conjuntamente na estruturação do material de apoio que foi disponibilizado aos acadêmicos que ingressaram na ES em março de 2011. Como os bolsistas já haviam cursado a disciplina, puderam expor suas dificuldades, opiniões e impressões, contribuindo fortemente para a reestruturação da disciplina. Adicionalmente, os bolsistas assumiram o papel de monitores de RP-I, oferecendo atendimento extraclasse e trabalhando como facilitadores no processo de ensinoaprendizagem.

Neste sentido, os bolsistas, os tutores e os acadêmicos desempenham papéis complementares. Os acadêmicos responsabilizam-se pelo entendimento do problema, pela criação de uma proposta de solução e pela implementação desta proposta. Os tutores realizaram o acompanhamento das atividades da disciplina e de seus grupos. Os bolsistas desempenham tarefas de apoio tanto para a operacionalização de RP-I, quanto apoio às equipes de trabalho. A Figura 1 ilustra o papel de cada um destes atores no andamento da disciplina de RP-I, sendo que cada um deve fazer a sua parte para que as engrenagens movimentem-se conforme o esperado.

\subsection{Organização da Disciplina de RP-I}

Como a disciplina envolve a utilização da ABP como abordagem de ensino-aprendizagem, há necessidade de se realizar um bom trabalho de planejamento e organização da mesma. Para facilitar a compreensão, explicaremos a 
operacionalização da disciplina ocorrida no primeiro semestre de 2011 em etapas: problema passa pela compreensão do contexto em que o problema está inserido e pela identificação das características pertinentes a solução, o

1. Planejamento da disciplina. Esta etapa é de res-

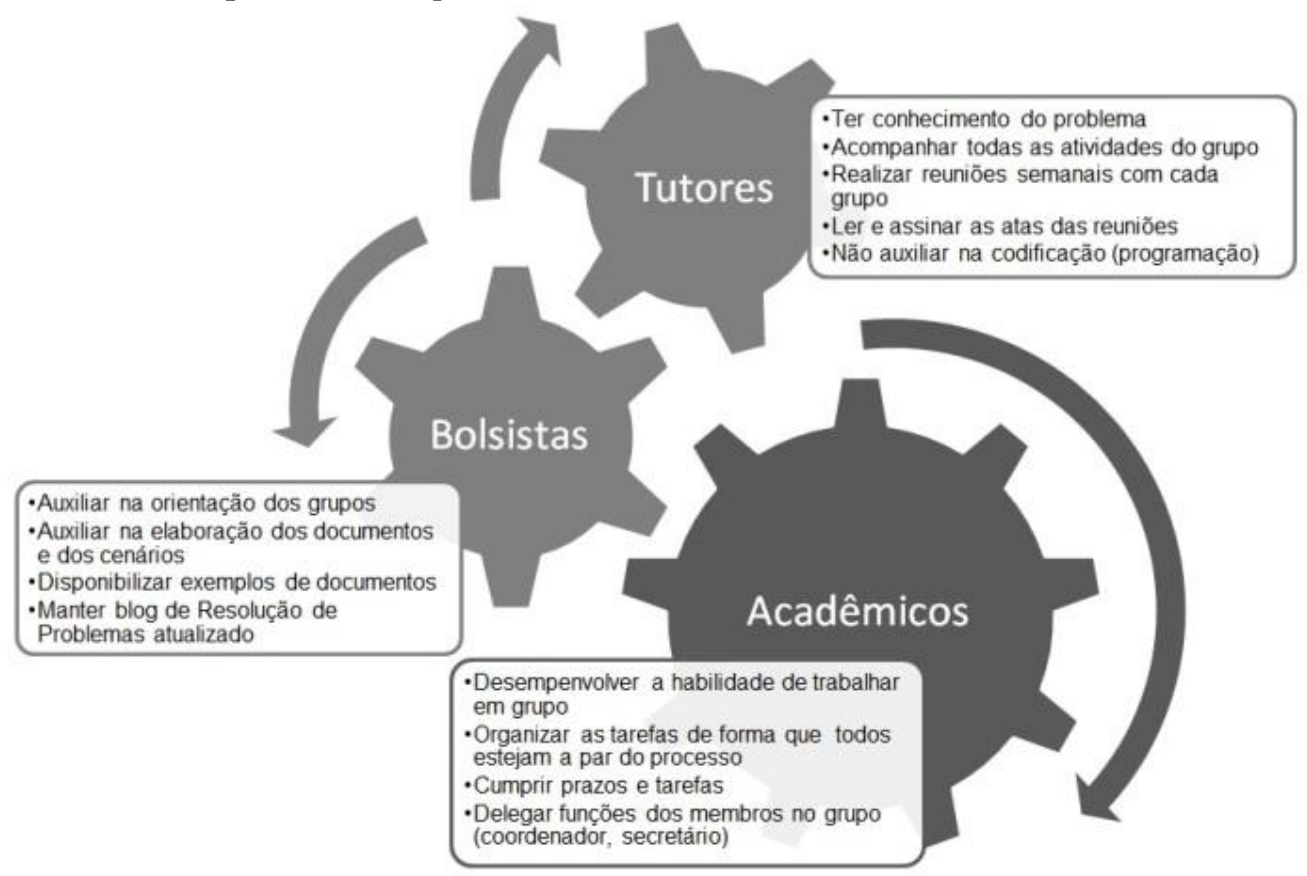

Figura 1: Papeis dos atores envolvidos nas atividades de Resolução de Problemas I.

ponsabilidade dos tutores com o acompanhamento dos bolsistas. Nela, foi feito um trabalho de levantamento das metas a serem atingidas com a disciplina e, principalmente, os caminhos para atingi-las. A partir das metas, iniciou-se a fase de elaboração dos enunciados dos problemas (julgou-se conveniente haver mais de um problema alvo, pois a turma era comporta por 54 alunos) e como seria a avaliação do trabalho das equipes. Os bolsistas expressaram suas impressões sobre a complexidade dos problemas e realizam a confecção dos artefatos para apoio e acompanhamento dos grupos. A organização dos grupos (ou equipes) também foi feita nesta etapa, onde idealizou-se a quantidade de alunos por grupo e a sua composição. Esta etapa aconteceu durante a primeira fase do semestre, enquanto os acadêmicos estavam envolvidos com as disciplinas de enfoque teórico;

2. Entendimento do problema. Esta etapa acontece no início da segunda fase do semestre, quando os acadêmicos são apresentados aos problemas alvo e organizam-se nas equipes de trabalho. Com o apoio dos tutores e dos bolsistas, os acadêmicos familiarizam-se com o problema que será seu desafio do semestre. $\mathrm{O}$ entendimento do qual é parte essencial para o sucesso do trabalho. Para tal, os acadêmicos foram incentivados a procurarem bibliografias específicas e poderiam recorrer aos tutores ou aos bolsistas para sanar suas dúvidas;

3. Levantamento de requisitos. Esta etapa representa a identificação dos requisitos que os usuários esperam do sistema a ser proposto pelos grupos de trabalho. O levantamento de requisitos pode acontecer, por exemplo, via entrevistas aos clientes (passando pela fase de planejamento do questionário a ser aplicado) ou pela elaboração de casos de uso. Analisando os requisitos obtidos, os acadêmicos passaram a criar suas hipóteses e evidências sobre a solução a ser proposta. Por se tratar da primeira experiência dos acadêmicos no levantamento de requisitos, os tutores acompanharam esta etapa estimulando a reflexão sobre os requisitos encontrados. Os bolsistas mantiveram-se a disposição para ajudar os acadêmicos;

4. Elaboração de uma proposta de solução. Nesta etapa os acadêmicos analisam os requisitos levantados e os sistematizam como as entradas e saídas esperadas de seus sistemas. O planejamento da proposta de solução inclui a avaliação 
de como os usuários irão interagir com o sistema. Em outras palavras, quais informações serão fornecidas, como elas serão fornecidas, quais informações são esperadas como resposta, em qual formato, etc. Adicionalmente, questões de como será a interface a ser oferecida aos usuários também são planejadas nesta etapa. Os tutores acompanham esta etapa estimulando a reflexão sobre o que está sendo proposto e os requisitos previamente levantados;

5. Elaboração de um sistema computacional. Uma vez que chegou-se a uma proposta de solução, onde há claramente uma definição de como o sistema deve funcionar, os grupos partem para a etapa de desenvolvimento do sistema. Nesta etapa aplicam-se os conhecimentos adquiridos nos demais componentes curriculares sobre programação e uso de ambientes computacionais. Na- turalmente, os grupos enfrentam dificuldades técnicas e tanto tutores quanto bolsistas ficam a disposição. Entretanto, a codificação é de inteira responsabilidade dos grupos, pois deve refletir a capacidade de desenvolvimento de sistemas dos acadêmicos.

Para deixar mais claro o papel de cada um dos atores durante o desenvolvimento da solução ao problema proposto, eles estão resumidos na Figura 2. Nela, tem-se uma visão geral do semestre em suas duas fases (à esquerda), relacionando as ações esperadas de cada um dos atores envolvidos durante as etapas de desenvolvimento da solução (à direita).

\subsection{Avaliações na Disciplina de RP-I}

Na primeira fase do semestre, a disciplina de Introdução a Engenharia de Software apresenta aos acadêmi-

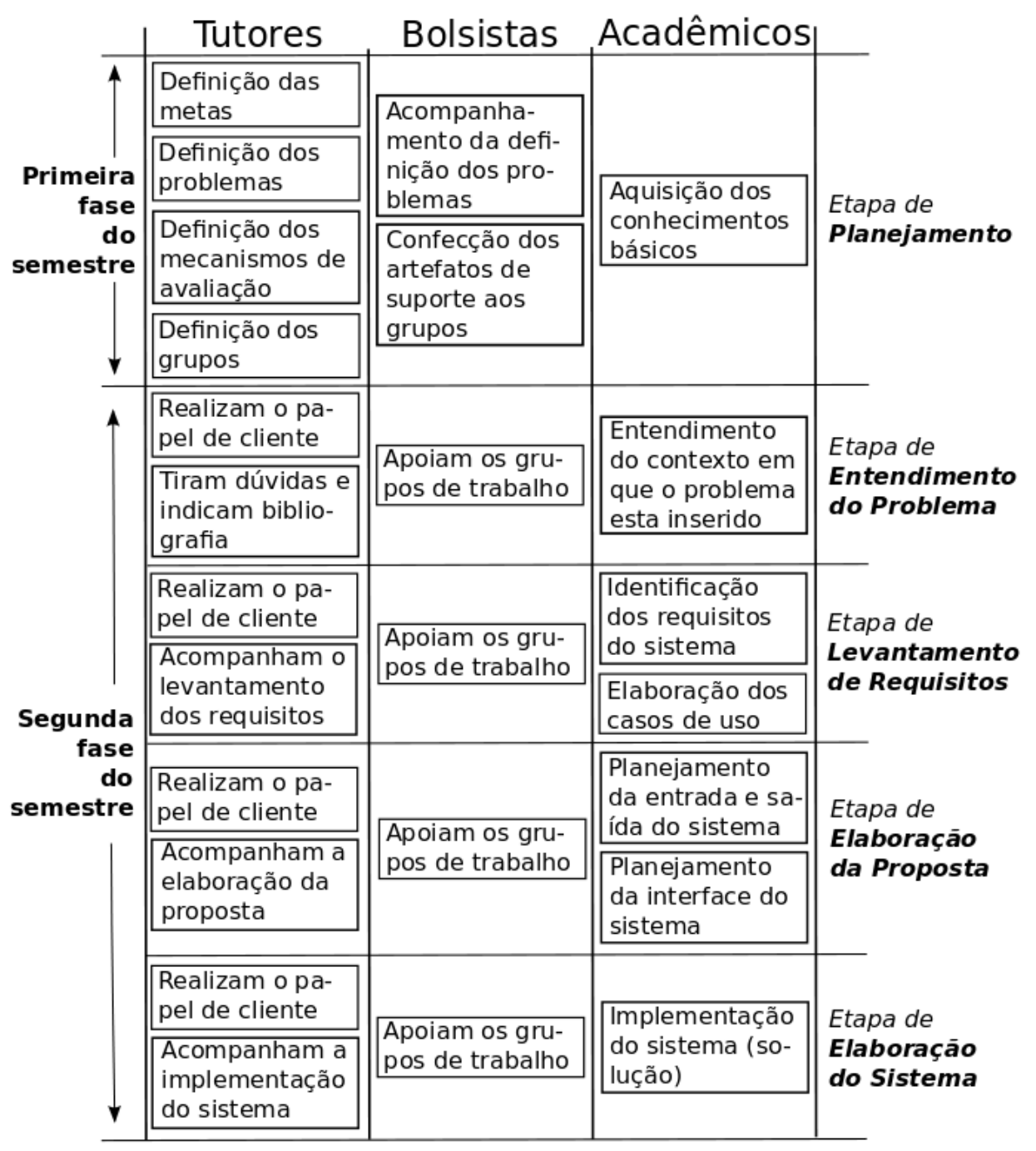

Figura 2: Atividades de responsabilidade dos envolvidos em RP-I, distribuídas nas fases do semestre (à esquerda) e nas etapas para a resolução dos problemas (à direita). 


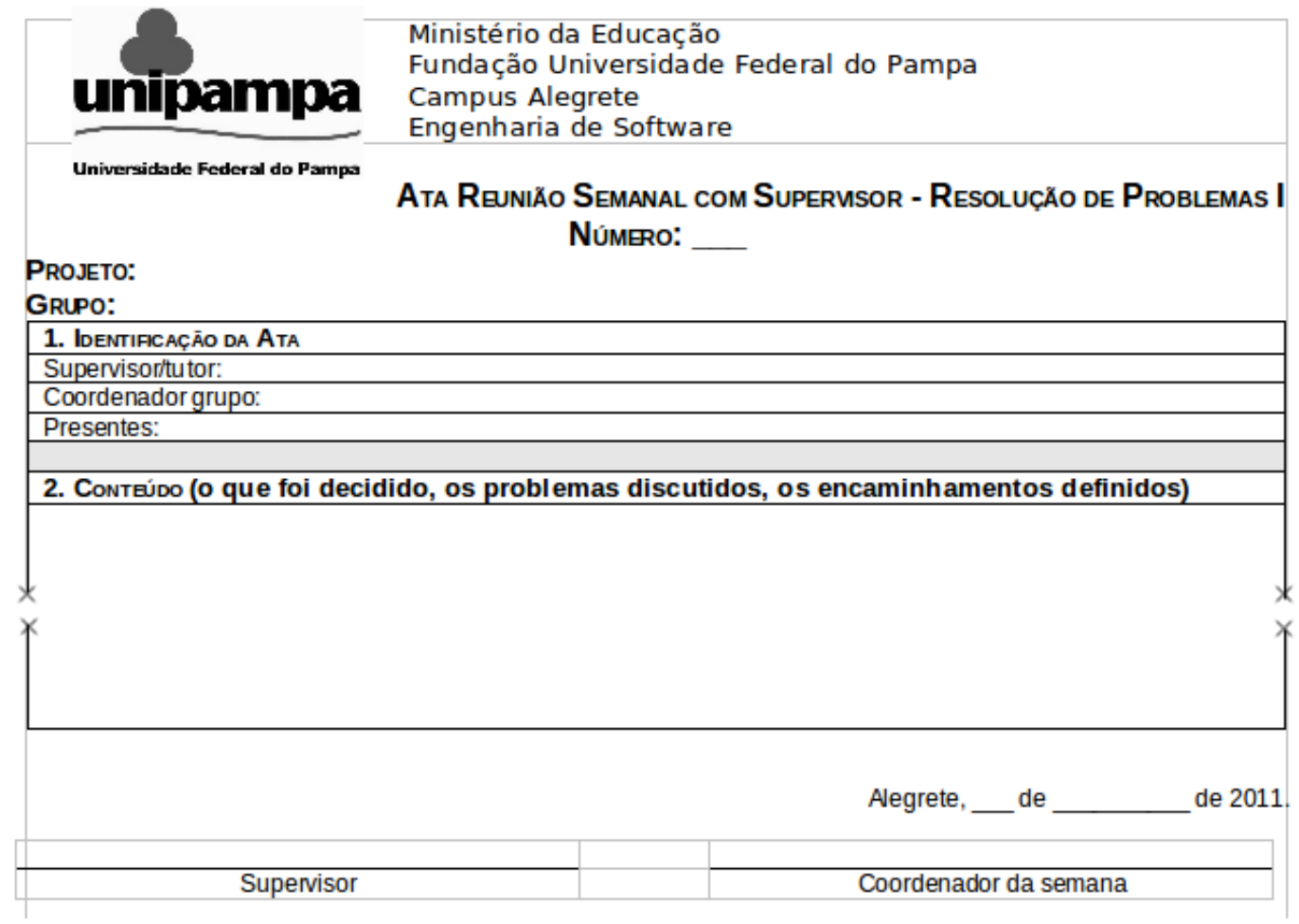

Figura 3: Ilustração do modelo de Ata de Reunião com o Tutor.

cos ingressantes uma visão preliminar dos conceitos e práticas básicas para o desenvolvimento de um software. Por exemplo, vimos na seção anterior que para propor uma solução é necessário fazer um levantamento dos requisitos do sistema. Logo, é importante que os alunos cheguem a esta etapa sabendo o que são requisitos, como classificá-los, como identificá-los a partir de questionamentos aos clientes, onde buscar mais informações, etc. A avaliação desta disciplina ocorre individualmente onde verifica-se o entendimento dos acadêmicos e sua preparação para RP-I.

Na segunda fase do semestre, as avaliações de RP-I voltam-se ao trabalho em equipe realizado pelos acadêmicos em prol da resolução do problema. Para que se pudesse acompanhar o andamento de todos os grupos, foram realizados três momentos, onde os grupos expunham seus avanços numa organização de seminário. Estes momentos de socialização e avaliação dos grupos foram chamados de checkpoints.

No primeiro checkpoint a meta dos grupos foi a de realizar a etapa de entendimento do problema e a de levantamento de requisitos. A meta do segundo checkpoint foi a de se apresentar a elaboração da proposta, incluindo a interface do software com os usuários (como acontece a entrada e saída de dados no sistema). Por fim, o terceiro checkpoint avaliou a elaboração do sistema computacional que representou a solução do problema alvo. O sistema foi demonstrado no seminário e foi posteriormente analisado e testado pelos tutores.

Além das avaliações coletivas representadas pelos checkpoints, os acadêmicos também foram avaliados individualmente pelos tutores. Como cada grupo possuía um tutor, ele tinha condições de verificar o comprometimento e empenho dos integrantes. Adicionalmente, os acadêmicos também emitiram suas impressões tanto sobre sua própria participação nas atividades quanto sobre a participação dos demais colegas de equipe.

Os artefatos utilizados na disciplina tiveram um importante papel tanto como mecanismo de referência, quanto como meio para analisar a evolução dos grupos. $\mathrm{Na}$ próxima seção são apresentados maiores detalhes sobre os artefatos.

\section{Artefatos Produzidos para Apoiar as Atividades de RP-I}




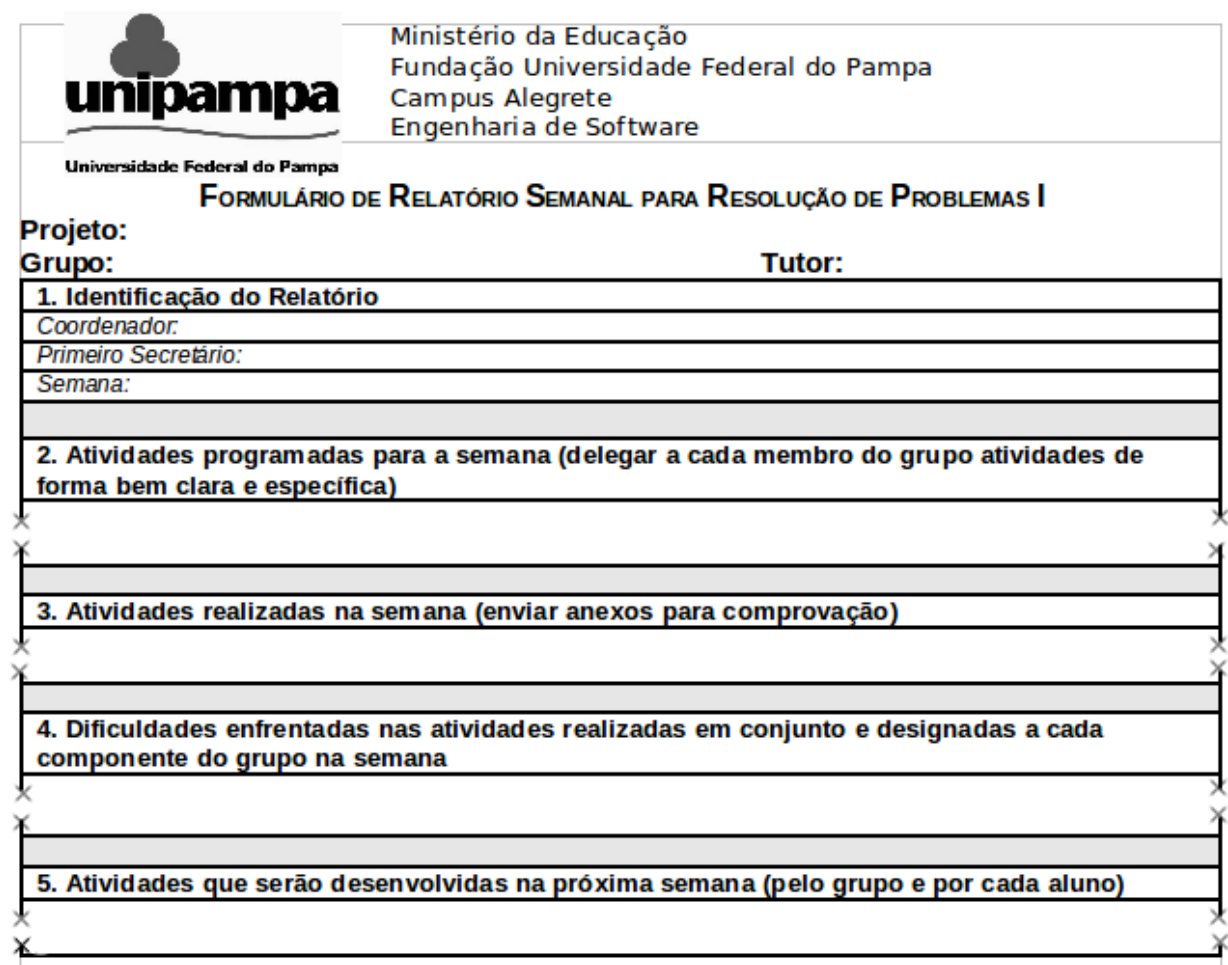

Figura 4: Ilustração do Modelo de Relatório Semanal.

Um dos artefatos produzidos para apoiar RP-I foi um blog (link: http://esunipampa.blogspot.com.br/). Ele serviu como um meio de fácil acesso, onde os acadêmicos tiravam dúvidas sobre a organização da disciplina e poderiam consultar trabalhos realizados nos semestres anteriores. Como os alunos relataram dificuldades com relação a questões técnicas, por exemplo a manipulação de arquivos em Java, os bolsistas também trabalharam na elaboração de um tutorial sobre o tema.

Uma das grandes preocupações relacionadas ao andamento de RP-I era com relação ao desenvolvimento do trabalho em equipe. No geral, os acadêmicos ingressam na universidade sem experiência com trabalho em equipe. É importante notar que a participação de todos nas atividades é fundamental, pois é desta participação que depende o aprendizado dos acadêmicos. A forma encontrada para ajudar neste processo foi através da confecção de documentos padronizados, os quais eram preenchidos pelas equipes, à medida que o trabalho evoluía. O preenchimento dos documentos estimulava a organização tanto das atividades quanto das responsabilidades de cada um. Estes documentos também proporcionavam meios para que os tutores pudessem acompanhar e verificar o andamento dos trabalhos.

Um destes documentos padronizados é a Ata de Reunião com o Tutor, cuja versão reduzida é mostrada na Figura 3. Nela, eram registrados todos os pontos importantes discutidos na reunião com o tutor. O objetivo deste documento é manter um registro comprobatório das tomadas de decisões. A cada reunião, o grupo preenchia o documento que era assinado tanto pelo tutor quanto pelo coordenador da equipe daquela semana. Para estimular a liderança e a distribuição das tarefas, a cada semana havia um coordenador diferente, sendo que cada acadêmico deveria ser o coordenador ao menos uma vez durante o semestre.

Outro artefato produzido foi o Relatório Semanal, cuja versão simplificada é mostrada na Figura 4. Este documento registra: (i) Quais atividades foram programadas para a semana e quem são os responsáveis por elas; (ii) Quais atividades foram efetivamente realizadas nesta semana; (iii) Quais foram as dificuldades enfrentadas durante o desenvolvimento das atividades; (iv) Quais atividades são previstas para a próxima semana. Este último torna-se o item (i) na semana seguinte. Este tipo de prática é comum em equipes de desenvolvimento que adotam um processo de desenvolvimento iterativo e incremental como o SCRUM [19].

Os documentos descritos acima visam estimular a organização do trabalho em equipe e criar meios para que se possa ter acesso a um histórico das decisões previamente tomadas. Entretanto, ainda resta as questões relativas as práticas da área de engenharia de software que devem acontecer enquanto as equipes de trabalho buscam por uma solução. Para ajudar neste aspecto, foi elaborado um Documento de Requisitos. Este documento é baseado 
em outros documentos já existentes e em bibliografias da área [25]. Um Documento de Requisitos documenta a solução que está sendo proposta, contendo um histórico das decisões tomadas pela equipe. Abaixo temos a estrutura básica deste documento:

1. Introdução: conceitos iniciais, escopo do produto, benefícios, limites, etc.;

2. Visão geral do sistema: descrição textual e abrangente do sistema e de suas funcionalidades;

3. Requisitos: descrição dos requisitos funcionais, não funcionais associados e suplementares levantados para o problema;

4. Requisitos Organizados: organização dos requisitos em casos de uso;

5. Projeto Externo: aspectos gerais do processo e do produto, caracterização dos usuários, tratamento de erros e menus de ajuda e componentes de interfaces com o usuário;

6. Projeto Interno: implementação, modelo conceitual, operações e diagrama de classe resumido (apenas com associações, sem atributos, métodos e multiplicidades).

Para apoiar a elaboração do Documento de Requisitos, foi disponibilizado um modelo com explicações, item a item, do que deveria ser exposto. Visando reduzir o impacto das dúvidas dos acadêmicos, por se tratar do primeiro Documento de Requisitos deles, também foi disponibilizado um documento de exemplo descrevendo a solução proposta pelos alunos bolsistas a um dos desafios de 2010, quando estes cursaram RP-I.

O Documento de Requisitos foi preenchido de forma incremental. Para o primeiro checkpoint, cuja meta foi entender o problema e levantar requisitos, os grupos confeccionaram a parte inicial do documento: Introdução, Visão geral do sistema, Requisitos e Requisitos Organizados. Esta versão foi avaliada pelos tutores e foram sugeridas melhorias a fim de que fosse possível atingir os objetivos do sistema. Para o segundo checkpoint, cuja meta era apresentar a elaboração da proposta e sua interface com os usuários, além de incorporar no Documento de Requisitos as melhorias sugeridas no primeiro checkpoint, os grupos deveriam apresentar também o Projeto Externo. Novamente a proposta foi avaliada e novas sugestões foram feitas. Por fim, no terceiro checkpoint, cuja meta era apresentar o sistema desenvolvido, o Documento de Requisitos estaria completo, incluindo as considerações sobre o Projeto Interno.

As etapas de acompanhamento e avaliação descritas nesta seção representam a implementação de aspectos importantes da ABP $[1,9,14,16,20,23]$ : registro e acompanhamento das atividades realizadas; organização do trabalho em equipe; reflexões sobre o andamento dos trabalhos; e avaliações intermediárias com fornecimento de retornos (feedbacks) sobre as atividades desenvolvidas.

A seguir serão descritas as particularidades da turma ingressante de 2011 relacionada a disciplina de RP-I.

\section{RP-I no Primeiro Semestre de 2011}

A turma de RP-I de março de 2011 era composta de 54 alunos. Para permitir um acompanhamento mais próximo, eles foram divididos em 10 grupos ou equipes de trabalho compostas por 05 ou 06 integrantes.

A disciplina contou com 05 professores tutores, onde cada professor acompanhou o andamento das atividades de 02 equipes de trabalho. Foram escolhidos 05 temas de trabalho sendo que cada tutor trabalhou sobre um mesmo assunto para os seus 02 grupos.

Para motivar os acadêmicos, os problemas propostos a turma foram baseados em necessidades do cotidiano da própria Universidade. Este é um aspecto interessante da ABP, onde a investigação ligada a um problema real estimula a busca por uma solução que não seja meramente a reprodução do raciocínio de um especialista [17].

O Núcleo de Tecnologia da Informação e Comunicação (NTIC) da UNIPAMPA, que é o órgão responsável por criar e manter os sistemas de Tecnologia da Informação e Comunicação (TIC), contribuiu listando alguns problemas que poderiam servir como base para a proposta de RP-I. Dentre estes problemas, foram selecionados os cinco desafios propostos a turma:

- Geração de senhas: esperando-se uma solução para a geração de senhas fortes, ou seja, difíceis de serem descobertas. Essas senhas seriam sugeridas aos usuários de um sistema como parte do processo de cadastramento de clientes;

- Verificação de senhas: esperando-se uma solução que teste o grau de dificuldade para descobrir uma determinada senha. Assim será possível tanto testar as senhas geradas pelo Gerador de Senhas, quanto validar senhas inseridas pelos usuários de um sistema;

- Histórico de senhas: esperando-se uma solução que evite que o usuário reuse senhas antigas. Por questões de segurança, espera-se que o histórico das senhas seja armazenado de maneira segura;

- Sugestão de Matrícula: esperando-se uma solução capaz de sugerir em quais disciplinas um aluno deve matricular-se. Para isso, é necessário levar em consideração o semestre corrente do alu- 
no, os horários das disciplinas e seus prérequisitos;

- Controle de Reserva de Salas: esperando-se uma solução para o gerenciamento de reservas e alocações de salas. Para isso, deve-se levar em conta as prioridades em reservas, as características das salas e as disponibilidades de horários. entregas de atividades, seja de Relatórios Semanais, seja do Documento de Requisitos a serem avaliados a cada checkpoint.

Na próxima seção serão discutidas os retornos obtidos dos acadêmicos de RP-I em 2011, através do preenchimento de um questionário de avaliação.

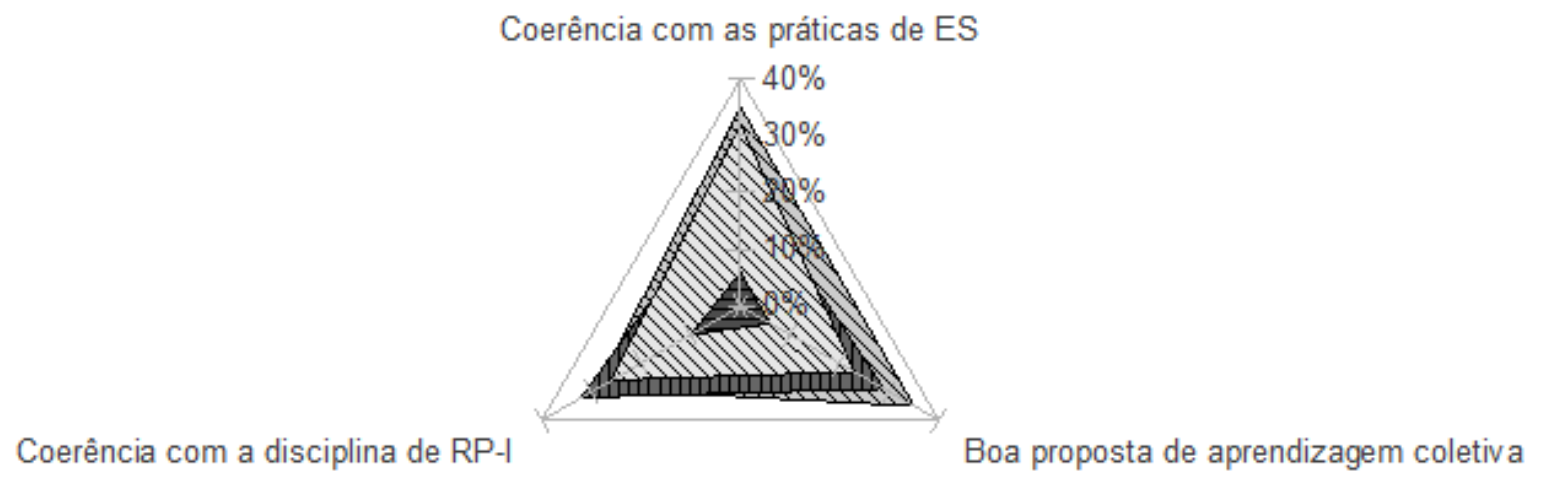

$\square$ Péssimo 目Regular $\Delta$ Bom $\mathbf{m}$ Muito Bom $\Delta$ Excelente

Figura 5: Representação gráfica das respostas dos acadêmicos da turma de 2011 com relação ao emprego da ABP.

Tabela 1: Avaliação dos acadêmicos da turma de 2011 com relação ao uso da ABP como abordagem de ensino-aprendizagem.

\begin{tabular}{|l|c|c|c|c|c|}
\hline \multicolumn{1}{|c|}{ Sobre a ABP: } & Péssimo & Regular & Bom & $\begin{array}{c}\text { Muito } \\
\text { Bom }\end{array}$ & Excelente \\
\hline $\begin{array}{l}\text { Coerência com } \\
\text { as práticas de ES }\end{array}$ & $0 \%$ & $6 \%$ & $32 \%$ & $23 \%$ & $\mathbf{3 5 \%}$ \\
\hline $\begin{array}{l}\text { Coerência com a } \\
\text { disciplina de } \\
\text { RP-I }\end{array}$ & $0 \%$ & $10 \%$ & $26 \%$ & $\mathbf{3 2 \%}$ & $29 \%$ \\
\hline $\begin{array}{l}\text { Boa proposta de } \\
\text { aprendizagem } \\
\text { coletiva }\end{array}$ & $3 \%$ & $6 \%$ & $23 \%$ & $29 \%$ & $\mathbf{3 5 \%}$ \\
\hline
\end{tabular}

O Ambiente Virtual de Aprendizagem Moodle da UNIPAMPA foi utilizado como repositório de materiais e informações relacionadas à disciplina. Nele os alunos encontravam desde o material sobre a Introdução a Engenharia de Software, indicações de livros e textos e os modelos de todos os artefatos produzidos para RP-I. Através do Moodle, os grupos também realizavam as

\section{Avaliação de RP-I sob a Ótica dos Acadêmicos}

Uma vez que a disciplina de RP-I foi planejada e implementada para a turma de 2011, foram colhidos retornos (feedbacks) dos acadêmicos para identificar os pontos positivos e negativos da proposta. O mecanismo escolhido foi através de um questionário, o qual foi respondido espontaneamente por 30 alunos do universo de 54. É com base nas respostas dos acadêmicos que iremos analisar o andamento da disciplina.

O questionário envolveu uma série de aspectos, entretanto neste artigo iremos focar na:

- Aceitação do uso da ABP como uma abordagem que auxilia no entendimento das práticas de engenharia de software;

- Autoavaliação dos acadêmicos com relação a sua postura no desenvolvimento das atividades em equipe;

- Avaliação dos acadêmicos com relação a postura do restante da equipe no desenvolvimento do 
trabalho;

- Avaliação dos artefatos produzidos para apoiar a
Os acadêmicos foram questionados com relação a coerência da $\mathrm{ABP}$ e as práticas de engenharia de software,

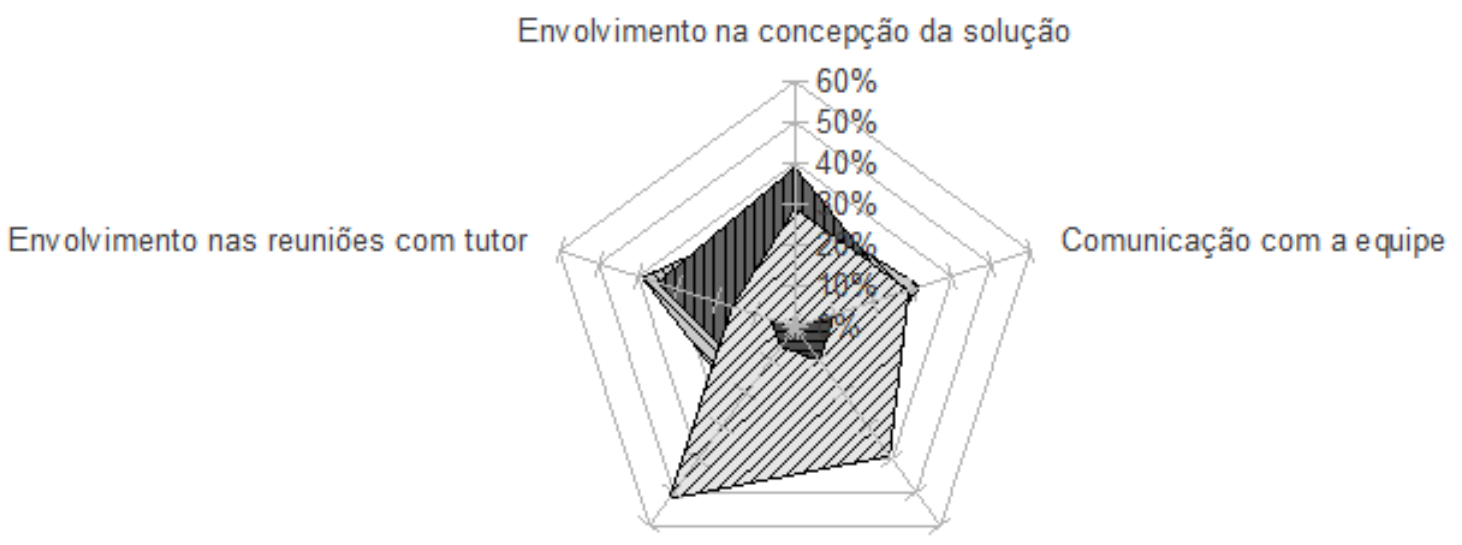

Envolvimento nas apresentações

Comunicação com os professores

\section{口Péssimo 日Regular छBom m Muito Bom $\Delta$ Excelente}

Figura 6: Representação gráfica das respostas dos acadêmicos da turma de 2011 sobre seu envolvimento no trabalho em equipe.

disciplina de RP-I;

A Tabela 1 resume as respostas dos acadêmicos quanto ao emprego da abordagem ABP como metodologia de ensino-aprendizagem vinculada a Engenharia de Softwa re. Para ajudar na visualização da tendência de resposta dos acadêmicos, a Figura 5 ilustra graficamente os percentuais em cada critério: péssimo, regular, bom, muito bom e excelente. Nela, percebe-se que a maior tendência das respostas variou entre excelente e muito bom.

Tabela 2: Autoavaliação dos acadêmicos da turma de 2011 com relação ao seu envolvimento na equipe de trabalho.

\begin{tabular}{|l|c|c|c|c|c|}
\hline Autoavaliação: & Péssimo & Regular & Bom & $\begin{array}{c}\text { Muito } \\
\text { Bom }\end{array}$ & Excelente \\
\hline $\begin{array}{l}\text { Envolvimento na } \\
\text { concepção da } \\
\text { solução }\end{array}$ & $0 \%$ & $0 \%$ & $29 \%$ & $\mathbf{3 9 \%}$ & $29 \%$ \\
\hline $\begin{array}{l}\text { Envolvimento } \\
\text { nas reuniões com } \\
\text { tutor }\end{array}$ & $0 \%$ & $6 \%$ & $16 \%$ & $35 \%$ & $\mathbf{3 9 \%}$ \\
\hline $\begin{array}{l}\text { Envolvimento } \\
\text { nas apresentações }\end{array}$ & $0 \%$ & $6 \%$ & $\mathbf{5 2 \%}$ & $16 \%$ & $23 \%$ \\
\hline $\begin{array}{l}\text { Comunicação } \\
\text { com os professo- } \\
\text { res }\end{array}$ & $0 \%$ & $10 \%$ & $\mathbf{3 9 \%}$ & $29 \%$ & $19 \%$ \\
\hline $\begin{array}{l}\text { Comunicação } \\
\text { com o restante da } \\
\text { equipe }\end{array}$ & $0 \%$ & $10 \%$ & $29 \%$ & $26 \%$ & $\mathbf{3 2 \%}$ \\
\hline
\end{tabular}

onde a maioria, 35\% das respostas, considera a mesma excelente, seguida de $32 \%$ que a considera boa. Quando foram questionados sobre a coerência entre a $\mathrm{ABP}$ e a organização da disciplina de RP-I, a maioria, 32\%, considera a mesma muito boa, seguida de $29 \%$ que a consideraram excelente. Com relação a considerar a $\mathrm{ABP}$ uma boa proposta de aprendizagem coletiva, 35\% dos acadêmicos manifestaram considerá-la excelente, seguidos de $29 \%$ que a considerou muito boa. Tais resultados configuram uma boa aceitação do uso da abordagem ABP como meio de incentivar o aprendizado da engenharia de software.

A manifestação dos acadêmicos demonstra que, mesmo com uma visão preliminar do curso, eles conseguem perceber as oportunidades geradas pela proposta diferenciada da ES: adquirir conhecimento específico e estimular habilidades relativas ao trabalho em equipe através de uma metodologia reconhecida como a ABP. Este tipo de retorno é muito importante aos docentes, pois serve de estímulo para que se continue o processo de concepção do curso com sua estrutura diferenciada.

A Tabela 2 apresenta os resultados coletados com relação a autoavaliação dos acadêmicos da turma de 2011. Este tipo de questionamento é importante para estimular a reflexão sobre o papel de cada um na construção do conhecimento. A Figura 6 representa graficamente a tendência das respostas dos acadêmicos, onde percebe-se a maior incidência nos critérios bom, muito bom e excelen- 
te.

Analisando item a item, a maioria dos alunos, 39\% deles, considerou muito bom o seu envolvimento na concepção da solução que foi proposta. Isto demonstra que já no primeiro semestre os acadêmicos percebem que a solução depende do seu próprio comprometimento. onamento é uma importante preparação para o futuro profissional. Por e-xemplo, há grandes chances deles precisarem expor a seus futuros clientes as vantagens e benefícios de seus produtos. Espera-se que no decorrer do curso, os estímulos propostos pela abordagem ABP façam com que os acadêmicos desenvolvam este tipo de aptidão.

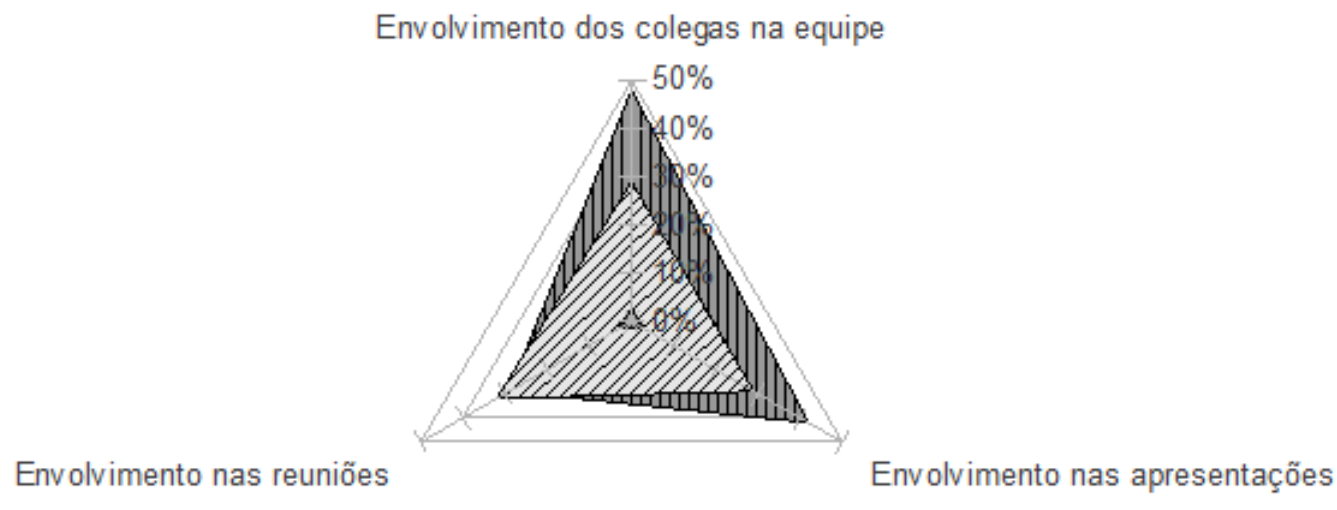

Péssimo 日Regular घBom mMuito Bom $\mathbf{\Delta E x c e l e n t e}$

Figura 7: Representação gráfica das respostas dos acadêmicos da turma de 2011 sobre o envolvimento dos demais colegas de equipe.

Tabela 3: Avaliação dos acadêmicos da turma de 2011 com relação ao envolvimento dos demais membros da equipe de trabalho.

\begin{tabular}{|l|c|c|c|c|c|}
\hline $\begin{array}{c}\text { Avaliação do } \\
\text { restante da } \\
\text { equipe }\end{array}$ & Péssimo & Regular & Bom & $\begin{array}{c}\text { Muito } \\
\text { Bom }\end{array}$ & Excelente \\
\hline $\begin{array}{l}\text { Envolvimento } \\
\text { dos colegas na } \\
\text { equipe }\end{array}$ & $0 \%$ & $3 \%$ & $29 \%$ & $\mathbf{4 8 \%}$ & $16 \%$ \\
\hline $\begin{array}{l}\text { Envolvimento } \\
\text { dos colegas nas } \\
\text { reuniões }\end{array}$ & $3 \%$ & $3 \%$ & $\mathbf{3 2 \%}$ & $29 \%$ & $29 \%$ \\
\hline $\begin{array}{l}\text { Envolvimento } \\
\text { dos colegas nas } \\
\text { apresentações }\end{array}$ & $3 \%$ & $3 \%$ & $29 \%$ & $\mathbf{4 2 \%}$ & $19 \%$ \\
\hline
\end{tabular}

Com relação ao envolvimento nas reuniões com os tutores, a maioria dos acadêmicos, 39\%, o consideram excelente, seguido de $35 \%$ que os consideraram muito bom. Já com relação ao seu envolvimento nas apresentações da solução (nos momentos de avaliação - checkpoints), 52\% deles o consideram bom. Os motivos que podem ter levado a este resultado muito provavelmente estão relacionados a exposição em público. Muitos acadêmicos têm dificuldades de se posicionar em frente aos colegas e tutores para expor o seu trabalho e responder a questionamentos. Entretanto, praticar este tipo de posici-
A comunicação com todos os professores, independente de ser ou não o seu tutor, é outro quesito que a maioria, 39\%, considerou bom. Este resultado nos leva a crer que precisamos buscar meios de aprimorar a comunicação com os acadêmicos na fase de concepção da solução, já que o apoio deve ocorrer para todos e não exclusivamente às equipes tutoradas. Com relação a comunicação com o restante da equipe, $32 \%$ dos acadêmicos a consideraram excelente, seguido de $29 \%$ que a consideraram boa. Isto demonstra que houve um entrosamento entre os membros das equipes, o que é um resultado positivo para uma primeira experiência focada no trabalho em equipe.

A Tabela 3 resume as respostas dos acadêmicos quando questionados sobre o envolvimento dos demais membros da equipe nas atividades desenvolvidas em RPI. Observando a representação gráfica das respostas na Figura 7, percebe-se que eles consideraram o envolvimento dos colegas, em sua maioria entre bom e muito bom.

Neste ponto da nossa análise, é interessante fazer um comparativo entre as respostas relativas ao envolvimento individual. O envolvimento dos colegas na equipe, o qual representa o quanto os colegas foram proativos no desen- 


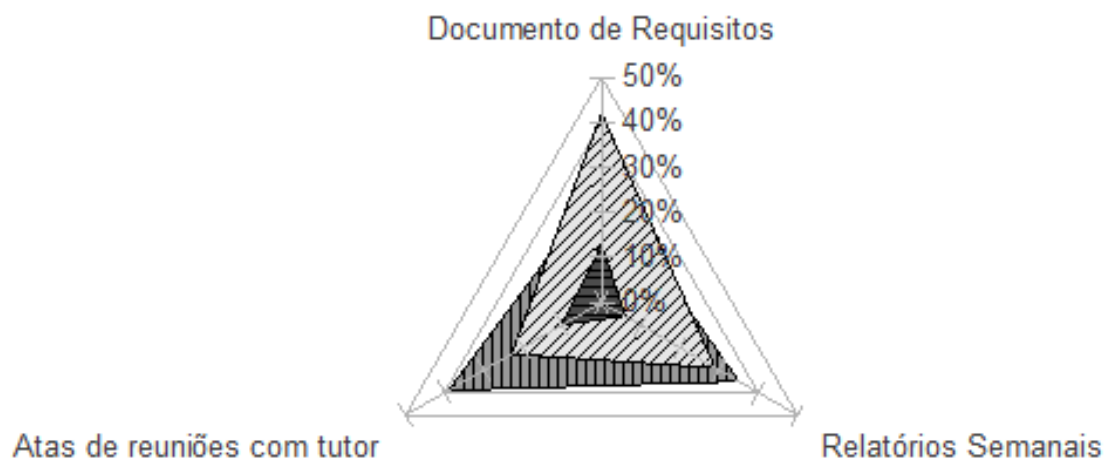

$\square$ Incompreensivel

Muito pouco compreensível $\oslash$ Compreensível em partes

पQuase totalmente compreensível $\Delta$ Compreensível

Figura 8: Representação gráfica das respostas dos acadêmicos da turma de 2011 com relação aos artefatos utilizados.

volvimento do trabalho, foi considerado muito bom em $48 \%$ das respostas. $\mathrm{Na}$ autoavaliação, o envolvimento na concepção da solução também foi considerado muito bom, mas com um percentual menor de 39\%. Esse tipo de resultado demonstra que os acadêmicos valorizam o engajamento da equipe como um todo nas atividades e que muito provavelmente, a solução só foi viável graças ao trabalho em equipe.

Tabela 4: Avaliação dos acadêmicos da turma de 2011 com relação aos artefatos produzidos para apoiar a disciplina de RP-I.

\begin{tabular}{|l|c|c|c|c|c|}
\hline $\begin{array}{c}\text { Artefa- } \\
\text { tos de } \\
\text { Apoio }\end{array}$ & $\begin{array}{c}\text { Incom- } \\
\text { preensí- } \\
\text { vel }\end{array}$ & $\begin{array}{c}\text { Muito } \\
\text { pouco } \\
\text { com- } \\
\text { preensí- } \\
\text { vel }\end{array}$ & $\begin{array}{c}\text { Com- } \\
\text { preensí- } \\
\text { vel em } \\
\text { partes }\end{array}$ & $\begin{array}{c}\text { Quase } \\
\text { total- } \\
\text { mente } \\
\text { com- } \\
\text { preensí- } \\
\text { vel }\end{array}$ & $\begin{array}{c}\text { Com- } \\
\text { preensí- } \\
\text { vel }\end{array}$ \\
\hline $\begin{array}{l}\text { Docu- } \\
\text { mento de } \\
\text { Requisi- } \\
\text { tos }\end{array}$ & $0 \%$ & $13 \%$ & $\mathbf{4 2 \%}$ & $26 \%$ & $16 \%$ \\
\hline $\begin{array}{l}\text { Atas de } \\
\text { reuniões } \\
\text { com } \\
\text { tutor }\end{array}$ & $0 \%$ & $10 \%$ & $23 \%$ & $\mathbf{3 9 \%}$ & $26 \%$ \\
\hline $\begin{array}{l}\text { Relató- } \\
\text { rios } \\
\text { Sema- } \\
\text { nais }\end{array}$ & $0 \%$ & $6 \%$ & $29 \%$ & $\mathbf{3 5 \%}$ & $26 \%$ \\
\hline
\end{tabular}

O envolvimento dos colegas nas reuniões com tutores foi considerado bom por $32 \%$ deles, já na autoavaliação a maioria, 39\%, considerou seu envolvimento excelente. Esse é um ponto interessante que demonstra que é preciso incentivar diálogos sobre o nível de envolvimento de cada um nas atividades, pois o que individualmente está sendo considerado, em sua maioria, excelente, recebe outra interpretação no coletivo.

A maioria dos acadêmicos, $42 \%$, considerou o envolvimento dos colegas nas apresentações da solução proposta (momentos de avaliação - checkpoints) muito bom, já na autoavaliação, este envolvimento foi considerado bom com um percentual de $52 \%$. Novamente voltando as questões de postura dos acadêmicos frente aos demais colegas e tutores, a maioria considera que o restante da equipe possui um envolvimento maior que o dele próprio. Mais uma vez, percebe-se a valorização do trabalho em equipe, que será exercitado e aprimorado ao longo do curso, contribuindo para a formação individual de cada um.

A Tabela 4 apresenta a avaliação dos acadêmicos referente aos principais artefatos desenvolvidos para apoiar a disciplina de RP-I. A avaliação considerou os critérios: incompreensível; muito pouco compreensível; compreensível em partes; quase totalmente compreensível e compreensível. A Figura 8 representa graficamente a tendência das respostas dos acadêmicos, que concentrou-se quase totalmente compreensível e compreensível em partes.

Com relação ao documento de requisitos, ele foi compreendido em partes por $42 \%$ dos acadêmicos. A compreensão deste documento requer uma boa base dos conceitos de engenharia de software. Por ser uma primeira experiência com este tipo de documentação, é normal que hajam dificuldades. Adicionalmente, no primeiro semestre os alunos ainda não estão habituados a buscar o conhecimento por conta própria e certamente gostariam de 
encontrar soluções para todas as suas dúvidas nas explicações item a item do documento de requisitos ou no exemplo de documento que lhes foi disponibilizado. Por outro lado, o surgimento das dúvidas faz parte do processo de construção do conhecimento esperado na disciplina. A própria estruturação da documentação e a organização da disciplina visa estimular as discussões com a equipe e a proatividade dos acadêmicos no esclarecimento de suas dúvidas, seja em bibliografias complementares, seja em conversas com os tutores, ou com os bolsistas, ou com os demais professores. Este tipo de postura será muito importante no futuro profissional de nossos acadêmicos.

Quanto aos outros dois artefatos de apoio: Atas de reuniões com tutor e Relatórios semanais, respectivamente, $39 \%$ e $35 \%$ dos acadêmicos avaliou como sendo quase totalmente compreensível. Isto era esperado já que alguns questionamentos foram levantados nas primeiras vezes em que os documentos foram utilizados. Além disso, foi notada uma certa resistência por parte de alguns integrantes em desempenhar o papel de coordenador do grupo. Este tipo de situação impactou na organização do grupo naquela semana, levando a um preenchimento incompleto destes documentos de apoio organizacional.

\section{Conclusão}

Os avanços tecnológicos e a difusão das TIC geram a necessidade de se repensar as abordagens de ensinoaprendizagem. É preciso encontrar meios de estimular os acadêmicos a criarem o hábito de acompanhar tais evoluções, ou seja, estimular a autoaprendizagem. Outro fator importante, é que há atualmente uma forte demanda por soluções interdisciplinares, as quais serão capazes de melhor contemplar os desafios contemporâneos. Adicionalmente, é esperado que eles desenvolvam durante a sua formação acadêmica características imprescindíveis hoje ao mercado de trabalho, tais como proatividade, iniciativa, responsabilidade, comprometimento, boa capacidade de comunicação e de trabalhar colaborativamente.

Este artigo buscou apresentar os esforços que vêm sendo feitos no curso de Engenharia de Software da UNIPAMPA a fim de prover uma base de aprendizado mais próxima ao que o mercado de trabalho almeja. $\mathrm{O}$ caminho que vem sendo seguido é o de proporcionar aos acadêmicos uma maior experiência em práticas coletivas. Assim, é possível estimular a formação de profissionais proativos, capazes tanto de atuar e de estar ciente de seu papel numa equipe quanto de considerarem os avanços tecnológicos em suas soluções. Para isso, optou-se pela abordagem de ensino-aprendizagem ABP (Aprendizagem Baseada em Problemas).

A ABP é uma abordagem centrada no aluno, onde o conhecimento é construído coletivamente através das vivências e desafios na resolução de problemas reais. A flexibilidade inerente desta abordagem permite sua adaptação ao contexto e às práticas da engenharia de software. Com a adoção da ABP, espera-se estimular habilidades profissionais que tornem-se um diferencial no futuro profissional de nossos egressos.

O foco das atividades descritas neste artigo esteve voltado à disciplina de Resolução de Problemas I (RP-I). Como trata-se do primeiro contato dos estudantes, tanto com a ABP, quanto com a engenharia de software, foram produzidos artefatos para auxiliar os acadêmicos. Estes artefatos visaram tanto estimular a organização do trabalho em equipe, quanto guiar a aplicação de conceitos básicos de engenharia de software durante a construção da solução.

Visando analisar a receptividade da proposta e os artefatos propostos, houve um acompanhamento da disciplina ofertada no primeiro semestre de 2011. Para esta turma, os temas dos problemas foram escolhidos dentro das próprias necessidades da Universidade, configurando assim um problema real, próximo da realidade dos acadêmicos. Isto levou os acadêmicos a tomarem suas próprias decisões na construção das soluções, fugindo da reprodução do raciocínio de um especialista.

Analisando os retornos obtidos da turma de 2011, foi possível identificar que os próprios acadêmicos reconhecem a importância das práticas coletivas em sua formação. Eles foram estimulados a avaliar o seu próprio envolvimento no trabalho em equipe e o envolvimento dos demais colegas. Este tipo de exercício estimula uma importante percepção nos acadêmicos, pois o sucesso da solução proposta, e o aprendizado de cada um, dependem diretamente do engajamento individual na equipe. Os retornos obtidos dos acadêmicos têm motivado o corpo docente a prosseguir empenhando esforços na estruturação do curso de ES da UNIPAMPA, com vistas a uma maior aproximação entre teoria e prática através do uso da ABP.

\section{Agradecimentos}

Gostaríamos de agradecer ao apoio financeiro fornecido pela UNIPAMPA para a realização deste trabalho em seu Programa de Bolsas de Desenvolvimento Acadêmico (PBDA) e pelo Edital de Inovação em Processos de Ensino e Aprendizagem 01/2010. Adicionalmente, estendemos nossos agradecimentos aos docentes Alessandro B. de Oliveira, Cristiano Tolfo e Ewerson L. de S. Carvalho. 


\section{Referências}

[1] U. F. Araújo, G. Sastre (orgs.). Aprendizagem baseada em Problemas no ensino superior. São Paulo: Summus, 2009.

[2] C. Z. Billa. Experiência de APB aplicado em Engenharia de Software. In: Anais do Congresso Internacional PBL 2012, Santiago de Cali, Colômbia, 2012.

[3] C. Z. Billa. O Método APB aplicado ao Curso de Engenharia de Software. In: Anais do Congreso Internacional PBL 2012, Santiago de Cali, Colômbia, 2012.

[4] C. Z. Billa, M. C. Cera. Utilizando Resolução de Problemas para aproximar Teoria e Prática na Engenharia de Software. In: Anais V Fórum de Educação em Engenharia de Software (FEES 2012) Evento integrante do XXVI Simpósio Brasileiro de Engenharia de Software (SBES 2012), Natal - RN. v. 05. p. 17-24, SBC, 2012.

[5] J. C. Braga. Diretrizes para o ensino interdisciplinar de engenharia de software. In Anais do FEESO9 - Fórum de Educação em Engenharia de Software, Fortaleza, Outubro 9, 2009.

[6] A. C. L. Corrêa, C. M. Vieira, L. M. G. Rolin, M. O. M. Soares, I. Francischetti. Programa de Desenvolvimento Docente (PDD) da Faculdade de Medicina de Marília (Famema): estratégia reflexiva para transformação das práticas. In: Anais do Congresso Internacional - PBL 2010: Aprendizagem Baseada em Problemas e Metodologias Ativas de Aprendizagem. São Paulo, SP, 2010.

[7] A. M. da Cunha, G. B. Silva, J. de Almeida Monte-Mor, M. A. P. Domiciano, R. G. Vieira. Estudo de caso abrangendo o ensino interdisciplinar de engenharia de software. In Anais do FEESO8 - Fórum de Educacao em Engenharia de Software, Campinas-SP, Brasil, 2008.

[8] M. H. Dal Forno, H. R. Teixeira, G. S. Jaques, M. C. Cera, V. G. Vieira, Aprendizagem Baseada em Problemas aplicado a Engenharia de Software: Suporte a disciplina de Resolução de Problemas I. In: Anais do Congresso Internacional PBL 2012, Santiago de Cali, Colômbia, 2012.

[9] R. de O. Duarte, P. F. D. Garcia. Metodologia de Ensino Orientada a Projetos e Criação de Material Didático aplicada ao Projeto de Processadores. In: Anais do Workshop sobre Educação em
Arquitetura de Computadores - WEAC 2011. Vitória-ES, Brasil, 2011.

[10] IEEE Computer Society Professional Practices Committee, SWEBOK - Guide to the Software Engineering Body of Knowledge, 2004.

[11] D. L. Notari, J. Bohn, E. Boff. Uma abordagem baseada em problemas para aprendizagem colaborativa de sistemas operacionais. In: Anais do Workshop sobre Educação em Informática WEI 2009. Bento Gonçalves-RS, Brasil, 2009

[12] M. de Oliveira Barros, R. M. de Araújo. Ensinando construção de software aplicada a sistemas de informação do mundo real. In Anais do FEES08 - Fórum de Educação em Engenharia de Software, Campinas-SP, Brasil, 2008.

[13] C. F. Pereira, R. A. Afonso, M. J. dos Santos, C. A. L de Araújo, M. Nogueira. Aprendizagem Baseada em Problemas (ABP) - Uma proposta inovadora para os cursos de engenharia. In: Simpósio de Engenharia de Produção - XIV SIMPEP 2007. 2007.

[14] J. A. M. Santos, M. F. Angelo. Análise de Problemas Aplicados em um Estudo Integrado de Programação utilizando PBL. In: Anais do Workshop sobre Educação em Informática WEI 2009.

[15] S. C. dos Santos, M. da Conceição Moraes Batista, A. P. Cavalcanti, J. O. Albuquerque, S. Meira. Usando pbl na qualificação de profissionais em engenharia de software. In Anais do FEESO8 - Fórum de Educação em Engenharia de Software, Campinas-SP, Brasil, Outubro 17, 2008.

[16] D. M. B. Santos, H. Saba. Avaliação do componente curricular interdisciplinar de engenharia de software. In Anais do FEES10 - Fórum de Educação em Engenharia de Software, Salvador, Bahia, Setembro 27, 2010.

[17] H. G. Schmidt. Foundations of problem-based learning: some explanatory notes. Medical Education, Limburg, v. 27, p. 422-432, 1993.

[18] M. Schots, R. Santos, A. Mendonca, C. Werner. Elaboração de um survey para a caracterização do cenário de educação em engenharia de software no Brasil. In Anais do FEES09 - Fórum de Educação em Engenharia de Software, Fortaleza, Outubro 9, 2009.

[19] K. Schwaber. Agile project management with Scrum. Redmond, WA: Microsoft Press, 2004.

[20] R. de A. Segura, C. F. de Araújo Júnior, I. F. Silveira. Aprendizagem Baseada em Problemas 
Apoiada por Ambientes Virtuais: um Estudo de Caso em Banco de Dados. In: Anais do Workshop sobre Educação em Informática - WEI 2009.

[21] D. S. M. Solarte, M. C. C. Baranauskas. Aprendizagem Colaborativa Baseada em Problemas (ACBP): Um Modelo Conceitual. Technical Report - IC-08-013. May - 2008.

[22] D. S. M. Solarte, M. C. C. Baranauskas. Resolução de Problemas e Colaboração a Distância: Modelo, Artefatos e Sistema. Revista Brasileira de Informática na Educação, v. 17, p. 21-35, 2009.

[23] W. L. de Souza, B. L. G. dos Santos, E. F. Z. Santana, E. C. Gatto, F. C. Duarte, G. B. de Freitas, I. V. Custódio, J. M. T. Portocarrero, P. M. de Ávila, R. A. P. Almeida. Utilizando PBL no ensino de Computação Ubíqua. In: Anais do XXX Congresso da Sociedade Brasileira de Computação - WEI - XVIII Workshop sobre Educação em Computação. SBC. 2010.

[24] The Join Task Force on Computing Curricula IEEE Computer Society and Association for Computing Machinery. Software Engineering 2004: Curriculum Guidelines for Ungraduated Degree Programs in Software Engineering, A Volume of the Curricula Computing Series, 2004.

[25] R. Wazlawick. Análise e Projeto de Sistemas de Informação Orientados a Objetos. 2a ed. Campus, 2004. 